ISSN 2078-5097. Вісн. Львів. ун-ту. Сер. прикл. матем. та інф. 2018. Вип. 26. С. 70-89

Visnyk of the Lviv University. Series Appl. Math. and Informatics. Issue 26. P. 70-89

UDC 517.925;519.6

\title{
DIRECT METHOD OF LIE-ALGEBRAIC DISCRETE APPROXIMATIONS FOR ADVECTION EQUATION
}

\author{
A. Kindybaliuk ${ }^{1}$, M. Prytula ${ }^{2}$
}

13Shape Ukraine, Poliova 21, Kyiv, 03056, e-mail: kindybaluk.arkadii@outlook.com

${ }^{2}$ Львівський національний університет імені Івана Франка, вул. Університетська, 1, Львів, 79000, e-mail: mykola.prytula@gmail.com

We propose the direct method of Lie-algebraic discrete approximation for numerical solving the Cauchy problem for advection equation in this paper. Discretization of the equation is performed by means of the Lie-algebraic quasi representations for space variables of the equation and by means of Taylor series expansion and small parameter method for the time variable. Such combination of approaches leads to a factorial rate of convergence with respect to all variables in the equation if the quasi representations for differential operator are built by means of Lagrange interpolation. The approximation properties and error estimations for the proposed scheme are investigated. The factorial rate of convergence for the proposed numerical scheme has been proven.

Key words: direct method of Lie-algebraic discrete approximations, advection equation, finite dimensional quasi representation, Lagrange polynomial, small parameter method, factorial convergence.

\section{INTRODUCTION}

The advection equation is the partial differential equation that governs the motion of a conserved scalar field as it is advected by a known velocity vector field. It has many applications in the different fields: physics, engineering and earth sciences $[18,19]$. Hence effective numerical solution is an important problem besides the variety of different approaches $[1,8,18]$.

We propose a numerical scheme built via direct method of Lie-algebraic discrete approximations for advection equation and prove the factorial rate of convergence of numerical scheme. The proposed numerical scheme, maintaining the same accuracy as a generalized method of Lie-algebraic discrete approximations, requires significantly less arithmetic operations.

The generalized method of Lie-algebraic method was introduced in [3] and developed in [4, 20-22], which is based on classic Lie-algebraic method of discrete approximations. The history of classical approach, open questions in this field and further development guidelines are analyzed in [1]. Key findings of classical approach may be found in $[6,7,9,11-17,23,24]$.

The main problem analyzed in these papers is the Cauchy problem for evolution equation which is considered in a bounded domain $\Omega:=(a, b) \subset R$ with time limit $T<+\infty$ and cylinder $Q_{T}=\Omega \times(0, T]$ :

$$
\left\{\begin{array}{l}
\text { find function } u=u\left(x_{1}, x_{2}, \ldots, x_{q}, t\right) \text { such, that } \\
u_{t}=K(t, x ; \partial) u+f(x, t), x \in \Omega \subset R^{q}, t>0, \\
\left.u\right|_{t=0}=\varphi(x) \in B,
\end{array}\right.
$$

(C) Kindybaliuk A., Prytula M., 2018 
Arkadii Kindybaliuk, M. Prytula

where $B$ denotes some functional Banach space, linear operator $K$ is assumed to be a formal polynomial of elements from the Lie-algebra $\{x, \partial / \partial x, 1\}$ and can be represented as

$$
K=a_{k} \frac{\partial^{k}}{\partial x^{k}}+a_{k+1} \frac{\partial^{k+1}}{\partial x^{k+1}}+\ldots+a_{k+p} \frac{\partial^{k+p}}{\partial x^{k+p}},
$$

where $a_{k+i} \in R$ for all $i=\overline{0, p}$ and $a_{k} \neq 0$ and $k \geq 1$.

Similarly, as in Calogero's method, the Heisenberg-Weyl algebra $G=\bigoplus_{j=1}^{q}\left\{x_{j}, \partial / \partial x_{j}, 1\right\}$ has been used as a basic algebraic tool for constructing the corresponding discrete approximations $X_{j}^{(n)}, Z_{j}^{(n)}, I^{(n)} \in \underset{j=1}{\otimes} R^{n_{j}}$.

Using q-dimensional Lagrange interpolation scheme problem (1.1) is reduced to the Cauchy problem in the following form:

$$
\left\{\begin{array}{l}
\text { find function } u_{(n)}=u_{(n)}(t) \text { such, that } \\
\frac{d u_{(n)}}{d t}=K_{(n)} u_{(n)}+f_{(n)}, t>0 \\
\left.u_{(n)}\right|_{t=0}=\varphi_{(n)} \in B_{(n)},
\end{array}\right.
$$

where $K_{(n)}$ denotes finite dimensional quasi representation of differential operator $K$, and $B_{(n)}$ denotes finite dimensional space of approximations. System (1.2) is solved by means of Euler's or Runge-Kutta's method [1, 7, 9, 13].

Since reduced problem (1.2) is solved making use of some numerical algorithm the rate of convergence by time variable is constrained by the convergence rate of the method based on, hence Lie-algebraic discrete approximations for space variables rate of convergence is factorial $[7,9]$.

This restriction led to development of the Generalized Method of Lie-algebraic discrete approximations proposed in [3], convergence rate for the time variable becomes factorial [20]. The main idea of generalized method of Lie-algebraic discrete approximations is the following: according to [3,4] there was introduced the substitution $u(x, t)=v(x, t)+\varphi(x)$ for the Cauchy problem:

$$
\left\{\begin{array}{l}
\text { find function } u=u(x, t) \in V \text { such, that } \\
u_{t}=K u+f, \forall(x, t) \in Q_{T}, \\
\left.u\right|_{t=0}=\varphi \in V,
\end{array}\right.
$$

where $\varphi=\varphi(x) \in V$ denotes initial conditions, $f=f(x, t) \in C$ represents internal sources and $K$ denotes the differential operator of a problem (1.3). The idea of such substitution was to reduce the computation effort maintaining accuracy which was demonstrated in the case of boundary value problem for elliptic equation [2]. This leads to considering the auxiliary Cauchy problem with homogeneous initial condition

$$
\left\{\begin{array}{l}
\text { find function } v=v(x, t) \in V \text { such, that } \\
v_{t}=K v+K \varphi+f, \forall(x, t) \in Q_{T}, \\
\left.v\right|_{t=0}=0 .
\end{array}\right.
$$


The solution of problem (1.4) has been seek in the subspace of such functions which are homogeneous at the initial moment of time: $B=\left\{v \in V:\left.v\right|_{t=0}=0\right\}$. Denoting the structure elements in (1.4) by $A:=\partial / \partial t-K, \tilde{f}=K \varphi+f \in C\left(Q_{T}\right)$, there was obtained a problem for operator equation:

$$
\left\{\begin{array}{l}
\text { for given operator } A: B \rightarrow C \text { and element } \tilde{f} \in C, \\
\text { find element } v \in B \text { such, that } A v=\tilde{f} .
\end{array}\right.
$$

The Cauchy problem was reduced into the problem for the operator equation. This operator equation was solved by means of the generalized method of Lie-algebraic discrete approximations and there has been proven its convergence for some particular cases [3, 2022].

However, such a computational scheme is relatively slow and requires computing costs, our goal is to construct a computational scheme that will provide the same accuracy and convergence rates, and as a result it will allow to get the numeric solution faster and with less computational cost, and moreover with the same accuracy.

This paper is constructed in the following way: we formulate the model problem to which we apply the proposed numerical scheme in second chapter, analytical foundations for the proposed numerical approach are discussed in the third chapter and its Lie-algebraic discretization of the recurrence relation is investigated in the fourth chapter. Numerical results with arithmetic operations count for the model problem are provided in the fifth chapter.

\section{PROBLEM FORMULATION}

Considering a bounded domain $\Omega:=(a, b) \subset R$, time limit $T<+\infty$, cylinder $Q_{T}=\Omega \times(0, T]$ we take the Banach spaces $V=C_{x, t}^{1,1}\left(Q_{T}\right) \cap C\left(\bar{Q}_{T}\right), C=C\left(Q_{T}\right)$ and formulate the Cauchy problem

$$
\begin{cases}\text { find function } u=u(x, t) \in V \text { such, that } \\ u_{t}+c u_{x}=0, & (x, t) \in \Omega_{T}=\Omega \times(0, T] \\ \left.u\right|_{t=0}=\varphi(x), & \varphi \in W^{\infty, \infty}((-|c| T,|c| T) \cup \bar{\Omega})\end{cases}
$$

where the constant $c \in R$ denotes the advection velocity parameter, $\varphi=\varphi(x) \in V$ denotes the initial conditions. According to [2-4] we make of use the introduced substitution $u(x, t)=v(x, t)+\varphi(x)$ into (2.1) which leads to considering the auxiliary Cauchy problem with homogeneous initial condition

$$
\left\{\begin{array}{l}
\text { find function } v=v(x, t) \in V \text { such, that } \\
v_{t}=-c v_{x}-c \varphi^{\prime}, \forall(x, t) \in Q_{T}, \\
\left.v\right|_{t=0}=0 .
\end{array}\right.
$$

The solution of problem (2.1) we seek using iterative approach method via Liealgebraic discrete approximations, i.e. direct method of Lie-algebraic discrete approximations. 


\section{ITERATIVE APPROACH AND ITS CONVERGENCE}

The main idea of the direct method of Lie-algebraic discrete approximation is to approximate the solution directly. First of all we make the analytical setup for the proposed approach.

Lemma 3.1. An integro-differential representation of the solution.

The function $u=u(x, t)$ in the integro-differential expression

$$
u(x, t)=\varphi(x)-c \int_{0}^{t}\left(\frac{\partial u(x, \tau)}{\partial x}\right) d \tau,
$$

is the solution of Cauchy problem (2.1).

Proof. Let us integrate the equation in (2.1) on the interval $(0, t)$

$$
\int_{0}^{t} \frac{\partial u}{\partial \tau} d \tau+c \int_{0}^{t} \frac{\partial u}{\partial x} d \tau=0, u(x, t)-u(x, 0)=-c \int_{0}^{t} \frac{\partial u}{\partial x} d \tau .
$$

With respect to initial condition, i.e. $\left.u\right|_{t=0}=\varphi(x)$ we obtain

$$
u(x, t)=\varphi(x)-c \int_{0}^{t} \frac{\partial u}{\partial x} d \tau .
$$

We can show that such defined function is the solution of the problem (2.1): if we differentiate (2.1) with respect to time variable we will get the equation we deal with:

$$
\frac{\partial u}{\partial t}=-c \frac{\partial u}{\partial x} \text {. }
$$

Next, we evaluate the $\left.u\right|_{t=0}$ :

$$
u(x, 0)=\varphi(x)-c \int_{0}^{0} \frac{\partial u}{\partial x} d \tau=\varphi(x) .
$$

Thus all requirements hold and the lemma has been proven.

Let us recall the generalized method of Lie-algebraic discrete approximations where the substitution $u(x, t)=\varphi(x)+v(x, t)$ had been introduced in order to proceed to Cauchy problem with homogeneous initial condition. In current case we have obtained a formula for the function $v(x, t)$, namely $v(x, t)=-c \int_{0}^{t} \frac{\partial u}{\partial x} d \tau$.

For further purposes let us denote the derivative of the function as $\varphi^{(k)}=d^{k} \varphi / d x^{k}$.

Lemma 3.2. The identity of series expansions.

The solution expansion

$$
u_{I}(x, t)=\sum_{k=0}^{+\infty} \tilde{u}_{k} \frac{t^{k}}{k !},
$$

where $\tilde{u}_{k}=(-1)^{k} c^{k} \varphi^{(k)}$, can be derived by means of iterative approach and this expansion is a Taylor series with respect to time variable.

Proof. At first we show that the series (3.2) can be derived by means of iterative approach. To accomplish this we recall the integro-differential representation of the solution (3.1) and set up an iterative process in the following form:

$$
u=u(x, t)
$$


According to [10] the starting element in recurrence sequence $u_{0}(x, t)=\varphi(x)$ can be obtained by setting $u_{-1}(x, t)=0$ in recurrence relation (3.3).

Let us evaluate $u_{k}(x, t)$ for $k=1,2,3$ :

$$
\begin{gathered}
u_{1}(x, t)=\varphi(x)-c \int_{0}^{t} \varphi^{\prime}(x) d \tau=\varphi(x)-c \varphi^{\prime}(x) t \\
u_{2}(x, t)=\varphi(x)-c \int_{0}^{t} \frac{\partial}{\partial x}\left(\varphi(x)-c \varphi^{\prime}(x) \tau\right) d \tau=\varphi(x)-c \varphi^{\prime}(x) t+c^{2} \varphi^{\prime \prime}(x) \frac{t^{2}}{2} \\
u_{3}(x, t)=\varphi(x)-c \int_{0}^{t} \frac{\partial}{\partial x}\left(\varphi(x)-c \varphi^{\prime}(x) \tau+c^{2} \varphi^{\prime \prime}(x) \frac{\tau^{2}}{2}\right) d \tau= \\
=\varphi(x)-c \varphi^{\prime}(x) t+c^{2} \varphi^{\prime \prime}(x) \frac{t^{2}}{2}-c^{3} \varphi^{\prime \prime \prime}(x) \frac{t^{3}}{3 !}
\end{gathered}
$$

Let us show that $u_{n}(x, t)=\sum_{k=0}^{n}\left((-1)^{k} c^{k} \varphi^{(k)}(x)\right) \frac{t^{k}}{k !}$. We assume that this statement holds for $u_{n}(x, t)$ and we check whether it holds for $u_{n+1}(x, t)$, i.e. $u_{n+1}(x, t)=\sum_{k=0}^{n+1}\left((-1)^{k} c^{k} \varphi^{(k)}(x)\right) \frac{t^{k}}{k !}$. Hence we consider the term $u_{n+1}(x, t)$ :

$$
\begin{gathered}
u_{n+1}(x, t)=\varphi(x)-c \int_{0}^{t} \frac{\partial}{\partial x}\left(u_{n}(x, \tau)\right) d \tau=\varphi(x)-c \int_{0}^{t} \frac{\partial}{\partial x}\left(\sum_{k=0}^{n}\left((-1)^{k} c^{k} \varphi^{(k)}(x)\right) \frac{\tau^{k}}{k !}\right) d \tau= \\
=\varphi(x)-c \int_{0}^{t}\left(\sum_{k=0}^{n}\left((-1)^{k} c^{k} \varphi^{(k+1)}(x) \frac{\tau^{k}}{k !}\right) d \tau=\varphi(x)-c \sum_{k=0}^{n}\left((-1)^{k} c^{k} \varphi^{(k+1)}(x) \int_{0}^{t} \frac{\tau^{k}}{k !} d \tau\right)=\right. \\
=\varphi(x)-c \sum_{k=0}^{n}\left((-1)^{k} c^{k} \varphi^{(k+1)}(x) \frac{t^{k+1}}{(k+1) !}\right)=\varphi(x)+\sum_{k=0}^{n}\left((-1)^{k+1} c^{k+1} \varphi^{(k+1)}(x) \frac{t^{k+1}}{(k+1) !}\right)= \\
=\varphi(x)+\sum_{k=1}^{n}\left((-1)^{k} c^{k} \varphi^{(k)}(x) \frac{t^{k}}{k !}\right)=\sum_{k=0}^{n+1}\left((-1)^{k} c^{k} \varphi^{(k)}(x) \frac{t^{k}}{k !} .\right.
\end{gathered}
$$

At the current moment we have shown that expansion (3.2) can be derived by means of the iterative approach (3.3). As a second step we derive the Taylor series for the problem (2.1) with respect to time variable and verify that obtained expression is identical to the expression stated in (3.2). Let us consider Taylor expansion at the initial moment of time:

$$
u_{n}(x, t)=u(x, 0)+\left(\left.\frac{\partial u}{\partial t}\right|_{t=0}\right) t+\left(\left.\frac{\partial^{2} u}{\partial t^{2}}\right|_{t=0}\right) \frac{t^{2}}{2 !}+\left(\left.\frac{\partial^{3} u}{\partial t^{3}}\right|_{t=0}\right) \frac{t^{3}}{3 !}+\ldots+\left(\left.\frac{\partial^{n} u}{\partial t^{n}}\right|_{t=0}\right) \frac{t^{n}}{n !},
$$

with the remainder $R_{n}(x, t)=\left(\left.\frac{\partial^{n+1} u}{\partial t^{n+1}}\right|_{t=\tau}\right) \frac{t^{n+1}}{n+1 !}$ having the following property

$$
u(x, t)-u_{n}(x, t)=R_{n}(x, t) .
$$


Although we have not explicit formulas for the $\left(\left.\frac{\partial^{k} u}{\partial t^{k}}\right|_{t=0}\right), k \geq 1$, nevertheless we can evaluate them with respect to initial condition and along the equation, i.e. $\frac{\partial u}{\partial t}=-c \frac{\partial u}{\partial x}$. For instance, one can evaluate $\left(\left.\frac{\partial u}{\partial t}\right|_{t=0}\right)$ and $\left(\left.\frac{\partial^{2} u}{\partial t^{2}}\right|_{t=0}\right)$ :

$$
\begin{gathered}
\left(\left.\frac{\partial u}{\partial t}\right|_{t=0}\right)=\left.\left(-c \frac{\partial u}{\partial x}\right)\right|_{t=0}=-c \frac{\partial}{\partial x}\left(\left.u\right|_{t=0}\right)=-c \varphi^{\prime}(x), \\
\left(\left.\frac{\partial^{2} u}{\partial t^{2}}\right|_{t=0}\right)=-\left.c \frac{\partial}{\partial x}\left(\frac{\partial u}{\partial t}\right)\right|_{t=0}=c^{2} \frac{\partial^{2}}{\partial x^{2}}\left(\left.u\right|_{t=0}\right)=c^{2} \varphi^{\prime \prime}(x) .
\end{gathered}
$$

To show that

$$
\left(\left.\frac{\partial^{k} u}{\partial t^{k}}\right|_{t=0}\right)=(-1)^{k} c^{k} \varphi^{(k)}(x), k \geq 1,
$$

we assume that expression of the above holds, and retrieve the following

$$
\left.\frac{\partial^{k+1} u}{\partial t^{k+1}}\right|_{t=0}=-c \frac{\partial}{\partial x}\left(\left.\frac{\partial^{k} u}{\partial t^{k}}\right|_{t=0}\right)=-c(-1)^{k} c^{k}\left(\varphi^{(k)}(x)\right)^{\prime}=(-1)^{k+1} c^{k+1} \varphi^{(k+1)}(x) .
$$

We see that expression holds and we have derived the expansion (3.2) using the symbolic computation tools.

As a third step we show the connection between these approaches. Let us consider

$$
\begin{gathered}
u_{n}(x, t)=\sum_{k=0}^{n}\left((-1)^{k} c^{k} \varphi^{(k)}(x)\right) \frac{t^{k}}{k !} \text {. The calculation of the }\left.\frac{\partial^{m} u_{n}}{\partial t^{m}}\right|_{t=0} \text { yields: } \\
\left.\frac{\partial u_{n}}{\partial t}\right|_{t=0}=\left(-c \varphi^{\prime}(x)+\left.\sum_{k=2}^{n}\left((-1)^{k} c^{k} \varphi^{(k)}(x) \frac{t^{k-1}}{(k-1) !}\right)\right|_{t=0}=-c \varphi^{\prime}(x),\right. \\
\left.\frac{\partial^{2} u_{n}}{\partial t^{2}}\right|_{t=0}=\left.\left(c^{2} \varphi^{\prime \prime}(x)+\sum_{k=2}^{n}\left((-1)^{k} c^{k} \varphi^{(k)}(x) \frac{t^{k-1}}{(k-1) !}\right)\right)\right|_{t=0}=c^{2} \varphi^{\prime \prime}(x), \\
\left.\frac{\partial^{m} u_{n}}{\partial t^{m}}\right|_{t=0}=\left.\left((-1)^{m} c^{m} \varphi^{(m)}(x)+\sum_{k=2}^{n}\left((-1)^{k} c^{k} \varphi^{(k)}(x) \frac{t^{k-1}}{(k-1) !}\right)\right)\right|_{t=0}=(-1)^{m} c^{m} \varphi^{(m)}(x) .
\end{gathered}
$$

Thus we have proven the expansion (3.2).

Lemma 3.3. Convergence of the iterative approach.

The sequence $\left\{u_{n}(x, t)\right\}$ defined in (3.2) is convergent to the exact solution, i.e.:

$$
\lim _{n \rightarrow \infty} u_{n}(x, t)=u(x, t),
$$

where $u(x, t)$ is the solution of the problem (2.1).

Proof. Since $u_{n}(x, t)$ is the Taylor expansion of the solution $u(x, t)$, so if $u_{n}(x, t)$ is convergent, then $u_{n}(x, t)$ converges to the exact solution $u(x, t)$. The remainder of Taylor series for function $u(x, t)$ has the following form: 


$$
R_{n}(x, t)=\left(\left.\frac{\partial^{n+1} u}{\partial t^{n+1}}\right|_{t=\tau}\right) \frac{t^{n+1}}{(n+1) !} .
$$

The exact solution of problem (2.1) is the following $u(x, t)=\varphi(x-c t)$, thus $\frac{\partial^{n+1} u}{\partial t^{n+1}}=(-1)^{n+1} c^{n+1} \frac{d^{n+1} \varphi}{d x^{n+1}}$ and since the function in the initial condition is bounded, i.e. $\varphi \in W^{\infty, \infty}((-|c| T,|c| T) \cup \bar{\Omega})$ we have:

$$
\left\|\frac{\partial^{n+1} u}{\partial t^{n+1}}\right\|_{\infty}=\sup _{(x, t) \in \Omega_{T}}\left|(-1)^{n+1} c^{n+1} \frac{d^{n+1} \varphi}{d x^{n+1}}\right|=|c|^{n+1}\left\|\frac{d^{n+1} \varphi}{d x^{n+1}}\right\|_{\infty} .
$$

Since $u(x, t)-u_{n}(x, t)=R_{n}(x, t)$ the estimation yields:

$$
\begin{gathered}
\left\|u-u_{n}\right\|_{\infty}=\left\|\frac{\partial^{n+1} u}{\partial t^{n+1}} \frac{t^{n+1}}{(n+1) !}\right\|_{\infty} \leq \frac{|c|^{n+1} T^{n+1}}{(n+1) !}\left\|\frac{d^{n+1} \varphi}{d x^{n+1}}\right\|_{\infty}, \\
\lim _{n \rightarrow \infty}\left\|u-u_{n}\right\|_{\infty}=\lim _{n \rightarrow \infty}\left(\frac{|c|^{n+1} T^{n+1}}{(n+1) !}\left\|\frac{d^{n+1} \varphi}{d x^{n+1}}\right\|_{\infty}\right)=\left\|\frac{d^{n+1} \varphi}{d x^{n+1}}\right\|_{\infty} \lim _{n \rightarrow \infty}\left(\frac{|c|^{n+1} T^{n+1}}{(n+1) !}\right)=0 .
\end{gathered}
$$

Thus $u_{n}(x, t)$ converges to the exact solution $u(x, t)$.

At current moment we should verify that $u_{I}(x, t)=\sum_{k=0}^{+\infty}(-1)^{k} c^{k} \varphi^{(k)}(x) \frac{t^{k}}{k !}$, is the solution of problem (2.1).

Having calculated auxiliary components:

$$
\begin{gathered}
\frac{\partial u_{I}}{\partial x}=\sum_{k=0}^{+\infty}(-1)^{k} c^{k} \varphi^{(k+1)}(x) \frac{t^{k}}{k !}, \\
\frac{\partial u_{I}}{\partial t}=\sum_{k=1}^{+\infty}(-1)^{k} c^{k} \varphi^{(k)}(x) \frac{t^{k-1}}{(k-1) !}=\sum_{k=0}^{+\infty}(-1)^{k+1} c^{k+1} \varphi^{(k+1)}(x) \frac{t^{k}}{k !},
\end{gathered}
$$

we can substitute them in the equation (2.1) and obtain the following expression:

$$
\begin{aligned}
\frac{\partial u_{I}}{\partial t}+ & c \frac{\partial u_{I}}{\partial x}=\sum_{k=0}^{+\infty}(-1)^{k+1} c^{k+1} \varphi^{(k+1)}(x) \frac{t^{k}}{k !}+c \sum_{k=0}^{+\infty}(-1)^{k} c^{k} \varphi^{(k+1)}(x) \frac{t^{k}}{k !}= \\
& =\sum_{k=0}^{+\infty}(-1)^{k+1} c^{k+1} \varphi^{(k+1)}(x) \frac{t^{k}}{k !}-\sum_{k=0}^{+\infty}(-1)^{k+1} c^{k+1} \varphi^{(k+1)}(x) \frac{t^{k}}{k !}= \\
& =\sum_{k=0}^{+\infty}\left((-1)^{k+1} c^{k+1} \varphi^{(k+1)}(x)-(-1)^{k+1} c^{k+1} \varphi^{(k+1)}(x)\right) \frac{t^{k}}{k !} \equiv 0 .
\end{aligned}
$$

Thus, lemma has been proven.

Proposition 3.1. Recurrence relation for the expansion terms.

Terms $\left\{\tilde{u}_{k}(x)\right\}_{k=1}^{n}$ in expression (3.2) can be computed by means of the following recurrence relation:

$$
\left\{\begin{array}{l}
\tilde{u}_{k+1}=-c \frac{d}{d x}\left(\tilde{u}_{k}\right) \\
\tilde{u}_{0}=\varphi
\end{array}\right.
$$


Proof. To prove this proposition we will use a Small Parameter Method. We seek solution as a formal expansion by small parameter:

$$
u_{\varepsilon}(x, t)=\sum_{k=0}^{\infty} \hat{u}_{k}(x, t) \varepsilon^{k}
$$

for the parameterized problem:

$$
\left\{\begin{array}{l}
\text { find function } u=u(x, t) \in V \text { such, that } \\
u_{t}=-\varepsilon\left(c u_{x}\right), \quad(x, t) \in \Omega_{T}=\Omega \times(0, T] \\
\left.u\right|_{t=0}=\varphi(x), \quad \varphi \in W^{\infty, \infty}((-|c| T,|c| T) \cup \bar{\Omega}) .
\end{array}\right.
$$

Substitution of formal series into parameterized problem yields the following expression:

$$
\sum_{k=0}^{\infty} \frac{\partial \hat{u}_{k}(x, t)}{\partial t} \varepsilon^{k}=c \varepsilon \sum_{k=0}^{\infty} \frac{\partial \hat{u}_{k}(x, t)}{\partial x} \varepsilon^{k} .
$$

After auxiliary algebraic calculations:

$$
\begin{aligned}
\sum_{k=0}^{\infty} \frac{\partial \hat{u}_{k}(x, t)}{\partial t} \varepsilon^{k} & =c \sum_{k=0}^{\infty} \frac{\partial \hat{u}_{k}(x, t)}{\partial x} \varepsilon^{k+1} \Rightarrow \sum_{k=0}^{\infty} \frac{\partial \hat{u}_{k}(x, t)}{\partial t} \varepsilon^{k}=c \sum_{k=1}^{\infty} \frac{\partial \hat{u}_{k-1}(x, t)}{\partial x} \varepsilon^{k} \Rightarrow \\
\Rightarrow & \frac{\partial \hat{u}_{0}(x, t)}{\partial t}+\sum_{k=1}^{\infty} \frac{\partial \hat{u}_{k}(x, t)}{\partial t} \varepsilon^{k}=c \sum_{k=1}^{\infty} \frac{\partial \hat{u}_{k-1}(x, t)}{\partial x} \varepsilon^{k}
\end{aligned}
$$

and as a conclusion we obtain:

$$
\frac{\partial \hat{u}_{0}(x, t)}{\partial t}+\sum_{k=1}^{\infty}\left(\frac{\partial \hat{u}_{k}}{\partial t}+c \frac{\partial \hat{u}_{k-1}}{\partial x}\right) \varepsilon^{k}=0 .
$$

Taking into account the initial conditions

$$
u_{\varepsilon}(x, 0)=\sum_{k=0}^{\infty} \hat{u}_{k}(x, t) \varepsilon^{k}=\varphi(x),
$$

we obtain the set of initial conditions:

$$
\left\{\begin{array}{l}
\left.\hat{u}_{0}\right|_{t=0}=\varphi(x), \\
\left.\hat{u}_{k}\right|_{t=0}=0, k \geq 1 .
\end{array}\right.
$$

The next step is that we introduce the set of Cauchy problems:

$$
\left\{\begin{array}{l}
\text { find functions } \hat{u}_{k}=\hat{u}_{k}(x, t) \in V \text { such, that } \\
\frac{\partial \hat{u}_{k}}{\partial t}=-c \frac{\partial \hat{u}_{k-1}}{\partial x} \quad(x, t) \in \Omega_{T}=\Omega \times(0, T], k \geq 1 \\
\left.\hat{u}_{k}\right|_{t=0}=0
\end{array}\right.
$$

and

$$
\begin{cases}\text { find function } \hat{u}_{0}=\hat{u}_{0}(x, t) \in V \text { such, that } \\ \frac{\partial \hat{u}_{0}}{\partial t}=0, & (x, t) \in \Omega_{T}=\Omega \times(0, T], k \geq 1 \\ \left.\hat{u}_{0}\right|_{t=0}=\varphi(x), & \varphi \in W^{\infty, \infty}((-|c| T,|c| T) \cup \bar{\Omega}) .\end{cases}
$$


The solution of the first problem is $\hat{u}_{0}(x, t)=\varphi(x)$. In fact, equation $\frac{\partial \hat{u}_{0}}{\partial t}=0$ shows that there are no changes during the evolution and $\left.\hat{u}_{0}\right|_{t=0}=\varphi(x)$ will not change during the all process, thus $\hat{u}_{0}=\varphi(x)$. On the other hand, the equation $\frac{\partial \hat{u}_{0}}{\partial t}=0$ leads that solution of this equation might be an arbitrary function that doesn't depend on time variable and since that $\hat{u}_{0}$ at initial moment of time has a constraint as $\left.\hat{u}_{0}\right|_{t=0}=\varphi(x)$ then the solution is $\hat{u}_{0}=\varphi(x)$.

Similar approach we use for the next problems. Evaluation of $\hat{u}_{1}$ yields the following expressions:

$$
\frac{\partial \hat{u}_{1}}{\partial t}=-c \frac{\partial \hat{u}_{0}}{\partial x} \Rightarrow \frac{\partial \hat{u}_{1}}{\partial t}=-c \varphi^{\prime}(x) \Rightarrow \hat{u}_{1}=-c \int \varphi^{\prime}(x) d t=-c \varphi^{\prime}(x) t+C_{1}(t),
$$

where $C_{1}(t)$ is an arbitrary function. Taking into account the initial condition $\left.\hat{u}_{1}\right|_{t=0}=0$ we obtain $C_{1}(t) \equiv 0$ and $\hat{u}_{1}=-c \varphi^{\prime}(x) t=\tilde{u}_{1}(x) t$.

We can assume that $\hat{u}_{k}(x, t)=(-1)^{k} c^{k} \varphi^{(k)}(x) \frac{t^{k}}{k !}=\tilde{u}_{k}(x) \frac{t^{k}}{k !}$, let us show that this expression holds for $k+1$ :

$$
\begin{gathered}
\frac{\partial \hat{u}_{k+1}}{\partial t}=-c \frac{\partial \hat{u}_{k}}{\partial x} \Rightarrow \frac{\partial \hat{u}_{k+1}}{\partial t}=(-1)^{k+1} c^{k+1} \varphi^{(k+1)}(x) \frac{t^{k}}{k !} \Rightarrow \\
\Rightarrow \hat{u}_{k+1}(x, t)=\int\left((-1)^{k+1} c^{k+1} \varphi^{(k+1)}(x) \frac{t^{k}}{k !}\right) d t=(-1)^{k+1} c^{k+1} \varphi^{(k+1)}(x) \int \frac{t^{k}}{k !} d t \Rightarrow \\
\hat{u}_{k+1}(x, t)=(-1)^{k+1} c^{k+1} \varphi^{(k+1)}(x) \frac{t^{k+1}}{(k+1) !}=\tilde{u}_{k+1} \frac{t^{k+1}}{(k+1) !} .
\end{gathered}
$$

Since $\quad \tilde{u}_{k}(x)=(-1)^{k} c^{k} \varphi^{(k)}(x) \quad$ and $\quad \tilde{u}_{k+1}(x)=(-1)^{k+1} c^{k+1} \varphi^{(k+1)}(x) \quad$ it implies that $\tilde{u}_{k+1}=-c \frac{d}{d x}\left(\tilde{u}_{k}\right)$ and it proves the proposition.

Before we move forward we have compare these three approaches which have been mentioned just above. It is obvious that iterative approach is computationally expensive, since at each step one should integrate an increasing expression. Taylor expansion requires symbolic computations and, thus, it cannot be used for the finite dimensional calculations. As our point of view, the most suitable approach, within these three approaches, is the method of small parameter. This approach allows fast symbolic computation in order to obtain the analytical solution and it is a good basis to make of use the Lie-algebraic discrete approximations. Next chapter is devoted to constructing the numerical scheme on top of recurrence relation via finite dimensional quasi representations.

\section{NUMERICAL SCHEME}

The main idea of numerical scheme construction for the direct method of Liealgebraic discrete approximation is to replace the elements from Lie-algebra $G=\{1, x, \partial / \partial x\}$ in recurrence relation (3.4) by theirs finite dimensional quasi 
Arkadii Kindybaliuk, M. Prytula

representations $\{1, X, Z\}$ respectively. Lagrange polynomials have been chosen as a tool for finite dimensional quasi representations construction.

\subsection{NUMERICAL SCHEME CONSTRUCTION}

Let $n_{x}$ denotes the count of nodes in domain $\Omega$ and $n_{t}$ denotes count of nodes in interval $[0, T]$ and $Q_{T, h}$ denotes the set of nodes $\left\{x_{i}\right\}_{i=0}^{n}$ and $\left\{t_{i}\right\}_{i=0}^{n}$. Lagrange polynomials $l_{j}(x)$ built at the nodes $\left\{x_{i}\right\}_{i=0}^{n}$ is the basis in finite dimensional space $B_{h}$. Let us denote the matrix $Z$ as finite dimensional quasi representation of the differential operator $d / d x$. The matrix $Z$ is built upon the rule $Z_{i j}=l_{j}^{\prime}\left(x_{i}\right)$ [14-16]. The key property of this matrix is such, that matrix $Z^{k}=(Z)^{k}$ approximates differential operator $d^{k} / d x^{k}$ and matrix $Z$ is nilpotent [14], i.e. there is some number $n$ that all further multiplications give nil matrix: $\forall k \geq n: Z^{k}=0$.

Having built all required quasi-representations we provide the following proposition as a key finding of this paper, namely the discrete recurrence relation as a Lie-algebraic discrete approximation of the recurrence relation.

Proposition 4.1. Finite dimensional recurrence relation for the expansion terms.

Terms $\left\{\tilde{u}_{k, h}\right\}_{k=1}^{n}$ in expression (3.2) can be computed by means of recurrence relation:

$$
\left\{\begin{array}{l}
\tilde{u}_{k+1, h}=-c Z \tilde{u}_{k, h}, \\
\tilde{u}_{0, h}=\varphi_{h},
\end{array}\right.
$$

which is the Lie-algebraic discretization of the recurrence relation (3.4)

Proof. Since $\tilde{u}_{k, h}$ is the finite dimensional quasi representation of $\tilde{u}_{k}$ and matrix $Z$ is the finite dimensional quasi representation of differential operator $d / d x$, then expression $\tilde{u}_{k+1}(x)=-c \frac{d}{d x}\left(\tilde{u}_{k}(x)\right)$ from (3.4) may be rewritten as a finite dimensional quasi representation $\tilde{u}_{k+1, h}=-c Z \tilde{u}_{k, h}$.

Since the matrix $Z$ is nilpotent, the length of a sequence $\tilde{u}_{k, h}$ in (4.1) is $n+1$. To prove that property one can rewrite the recurrence relation into the following form $\tilde{u}_{k, h}=-c^{k} Z^{k} \varphi_{h}$. When the index $k$ reaches the number $n_{x}$ we have $\tilde{u}_{k, h}=0, k \geq n_{x}$, since $Z^{n_{x}}=0[14]$.

\subsection{APPROXIMATION PROPERTIES}

Since the numerical scheme uses Lagrange interpolation and Lagrange polynomials, we need to discuss some issues regarding the approximation properties of Lagrange polynomials in the context of constructed numerical scheme.

Lemma 4.1. Derivative error bounds for Lagrange interpolation.

Let $v(x) \in W^{\infty, \infty}(\Omega)$ and $v_{I}(x)$ denotes the Lagrange interpolation of function $v(x)$ built at nodes $\left\{x_{i}\right\}_{i=0}^{n}$. Then the following estimation of the error bounds for Lagrange interpolation holds: 


$$
\left\|v^{(k)}-v_{I}^{(k)}\right\|_{\infty} \leq \frac{(\operatorname{diam} \Omega)^{n-k+1}}{(n-k+1) !}\left\|v^{(n+1)}\right\|_{\infty} .
$$

Proof. When interpolating the given function $v(x)$ by Lagrange polynomial $v_{I}(x)$ of degree $n$ at the nodes $\left\{x_{i}\right\}_{i=0}^{n}$ we get the remainder which can be expressed as $v(x)-v_{I}(x)=\omega_{n}(x) \frac{v^{n+1}(\xi)}{(n+1) !}, \xi \in \Omega$ and can be bounded as

$$
\left\|v-v_{I}\right\|_{\infty} \leq \frac{\left\|\omega_{n}(x)\right\|_{\infty}}{(n+1) !}\left\|v^{(n+1)}\right\|_{\infty}
$$

With estimation $\left\|\omega_{n}(x)\right\|_{\infty} \leq(\operatorname{diam} \Omega)^{n+1}$ we have the final estimation:

$$
\left\|v-v_{I}\right\|_{\infty} \leq \frac{(\operatorname{diam} \Omega)^{n+1}}{(n+1) !}\left\|v^{(n+1)}\right\|_{\infty} .
$$

Let us estimate the $\left\|v^{\prime}-v_{I}^{\prime}\right\|_{\infty}$. The derivative of the remainder with respect to space variable has the following form:

$$
v^{\prime}(x)-v_{I}^{\prime}(x)=\omega_{n}^{\prime}(x) \frac{v^{n+1}(\xi)}{(n+1) !}, \xi \in \Omega .
$$

Since function $\omega_{n}^{\prime}(x)$ is a sum of $n+1$ terms, each of them is a product containing $n$ units of $x-x_{i}$, then the estimation of $\left\|\omega_{n}^{\prime}(x)\right\|_{\infty} \leq(n+1)(\text { diam } \Omega)^{n}$ yields

$$
\left\|v^{\prime}-v_{I}^{\prime}\right\|_{\infty} \leq \frac{(\operatorname{diam} \Omega)^{n}}{n !}\left\|v^{(n+1)}\right\|_{\infty} .
$$

Let us estimate the $\left\|v^{\prime \prime}-v_{I}^{\prime \prime}\right\|_{\infty}$. The derivative of the remainder with respect to space variable has the following form:

$$
v^{\prime \prime}(x)-v_{I}^{\prime \prime}(x)=\omega_{n}^{\prime \prime}(x) \frac{v^{n+1}(\xi)}{(n+1) !}, \xi \in \Omega .
$$

The function $\omega_{n}^{\prime \prime}(x)$ is a sum of $n(n+1)$ terms, each of them is a product containing $n-1$ units of $x-x_{i}$. Thus the estimation of $\left\|\omega_{n}^{\prime}(x)\right\|_{\infty} \leq n(n+1)(\operatorname{diam} \Omega)^{n-1}$ yields

$$
\left\|v^{\prime \prime}-v_{I}^{\prime \prime}\right\|_{\infty} \leq \frac{(\operatorname{diam} \Omega)^{n-1}}{(n-1) !}\left\|v^{(n+1)}\right\|_{\infty} .
$$

And finally let us estimate the norm $\left\|v^{(k)}-v_{I}^{(k)}\right\|_{\infty}$. The derivative of the remainder with respect to space variable has the following form:

$$
v^{(k)}(x)-v_{I}^{(k)}(x)=\omega_{n}^{(k)}(x) \frac{v^{n+1}(\xi)}{(n+1) !}, \xi \in \Omega .
$$

The function $\omega_{n}^{(k)}(x)$ is a sum of $(n+1) n(n-1) .(n-k+1)$ terms each of them is a product containing $n-1$ units of $x-x_{i}$. Thus the estimation of $\left\|\omega_{n}^{(k)}(x)\right\|_{\infty} \leq(n+1) n(n-1) . .(n-k+1)(\operatorname{diam} \Omega)^{n-k+1}$ yields the final estimation: 


$$
\left\|v^{(k)}-v_{I}^{(k)}\right\|_{\infty} \leq \frac{(\operatorname{diam} \Omega)^{n-k+1}}{(n-k+1) !}\left\|v^{(n+1)}\right\|_{\infty} .
$$

Thus, the lemma is proven.

Let us introduce the cylinder norm for the function $v=v(x): R \rightarrow R:$ as a following functional: $\|v\|_{B_{h}}^{2}=\frac{1}{n+1} \sum_{i=0}^{n} v^{2}\left(x_{i}\right)$, being a norm in the finite dimensional space $B_{h}$. One can verify that the following inequality holds $\|v\|_{B_{h}} \leq\|v\|_{\infty}$.

In fact, it is easy to verify that inequality of above has place:

$$
\begin{aligned}
\|v\|_{B_{h}} & =\sqrt{\frac{1}{n+1} \sum_{i=0}^{n} v^{2}\left(x_{i}\right)} \leq \sqrt{\frac{1}{n+1} \sum_{i=0}^{n}\left(\max _{x_{i}}\left|v\left(x_{i}\right)\right|^{2}\right.} \leq \\
& \leq \sqrt{\frac{1}{n+1} \sum_{i=0}^{n}\left(\max _{x \in \Omega}|v(x)|^{2}\right.}=\max _{x \in \Omega}|v(x)|=\|v\|_{\infty} .
\end{aligned}
$$

Lemma 4.2. Derivative error bounds for quasi representation.

Let $v(x) \in W^{\infty, \infty}(\Omega)$ and $v_{I}(x)$ denotes the Lagrange interpolation of function $v(x)$ built at nodes $\left\{x_{i}\right\}_{i=0}^{n}$, matrix $Z^{k}$ as finite dimensional quasi representation of the differential operator $d^{k} / d x^{k}$, then the following estimation of the error bounds for finite dimensional quasi representations holds:

$$
\left\|v^{(k)}-Z^{k} v\right\|_{B_{h}} \leq\left\|v^{(k)}-v_{I}^{(k)}\right\|_{\infty}
$$

Proof. Since the norm of space $B_{h}$ is actually a norm of vector, we represent the difference $v^{(k)}-Z^{k} v$ as a vector at the nodes of interpolation $\left\{x_{i}\right\}_{i=0}^{n}$. We obtain the vector $\left\{v^{(k)}\left(x_{i}\right)\right\}_{i=0}^{n_{x}}$ for the expression $v^{(k)}$ and $\left\{v\left(x_{i}\right)\right\}_{i=0}^{n_{x}}$ for the element $v \in B$.

According to the construction of finite dimensional quasi representations we can verify that $\left(Z^{k} v\right)_{i}=v_{I}^{(k)}\left(x_{i}\right)$. To ensure that property let us consider the particular component of a vector $Z^{k} v$ :

$$
\left(Z^{k} v\right)_{i}=\left(l_{1}^{(k)}\left(x_{i}\right), \ldots, l_{n_{x}}^{(k)}\left(x_{i}\right)\right)\left(v\left(x_{i}\right), \ldots, v\left(x_{n_{x}}\right)\right)^{\mathrm{T}}=\sum_{j=0}^{n_{x}}\left(v\left(x_{j}\right) l_{j}^{(k)}\right)\left(x_{i}\right)=v_{I}^{(k)}\left(x_{i}\right) .
$$

As a conclusion of $\left(Z^{k} v\right)_{i}=v_{I}^{(k)}\left(x_{i}\right)$ we get the generalization: $\left(v^{(k)}-Z^{k} v\right)_{i}=\left(v^{(k)}-v_{I}^{(k)}\right)\left(x_{i}\right)$ which is used for the desired estimation:

$$
\left\|v^{(k)}-Z^{k} v\right\|_{B_{h}}=\sqrt{\frac{1}{n_{x}} \sum_{i=0}^{n_{x}}\left(\left(v^{(k)}-v_{I}^{(k)}\right)\left(x_{i}\right)\right)^{2}} \leq \sqrt{\frac{1}{n_{x}} \sum_{i=0}^{n_{x}}\left(\sup _{x \in \Omega}\left(v^{(k)}-v_{I}^{(k)}\right)(x)\right)^{2}} \leq\left\|v^{(k)}-v_{I}^{(k)}\right\|_{\infty} .
$$

Therefore the lemma is proven.

\subsection{CONVERGENCE AND ERROR ESTIMATION}

The key finding of this paper is the proposition of method which has almost the same properties regarding the convergence but has more comprehensive way in the constructing and implementation of the numerical scheme. Let us proceed to discussion concerning the convergence of numerical scheme. 
Theorem 4.1. Convergence of the direct Lie-algebraic numerical scheme.

Let $u=u(x, t)$ be the solution of the problem (2.1), $u_{n}=\sum_{k=0}^{n} \tilde{u}_{k} \frac{t^{k}}{k !}, \quad$ be the Taylor expansion of the solution and $u_{h}(x, t)=\sum_{j=0}^{n}\left[\left(\sum_{k=0}^{n} \tilde{u}_{k, h} \frac{t^{k}}{k !}\right) l_{j}(x)\right]$ be the finite dimensional solution. Then built numerical scheme (4.1) is convergent having the factorial rate of convergence:

$$
\left\|u-u_{h}\right\|_{B_{h}} \leq \frac{|c|^{n+1} T^{n+1}+(2 \max \{|c| T,(\operatorname{diam} \Omega)\})^{n+1}}{(n+1) !}\left\|\varphi^{(n+1)}\right\|_{\infty} .
$$

Proof. The norm $\left\|u-u_{h}\right\|_{B_{h}}$ can be split to two others norm,

$$
\left\|u-u_{h}\right\|_{B_{h}}=\left\|u-u_{n}+u_{n}-u_{h}\right\|_{B_{h}} \leq\left\|u-u_{n}\right\|_{B_{h}}+\left\|u_{n}-u_{h}\right\|_{B_{h}},
$$

where the first norm $\left\|u-u_{n}\right\|_{B_{h}}$ represents the accuracy of approximation of the solution by means Taylor expansion and second form represents the error of Taylor series approximation by means of Lie-algebraic finite dimensional quasi representations. Using lemmas 3.3 and 4.2 we obtain the estimation for the first norm:

$$
\left\|u-u_{n}\right\|_{B_{h}} \leq\left\|u-u_{n}\right\|_{\infty} \leq \frac{|c|^{n+1} T^{n+1}}{(n+1) !}\left\|\frac{d^{n+1} \varphi}{d x^{n+1}}\right\|_{\infty} .
$$

Decomposition of the norm $\left\|u_{n}-u_{h}\right\|_{B_{h}}$ implies the following:

$$
\left\|u_{n}-u_{h}\right\|_{B_{h}}=\left\|\sum_{k=0}^{n} \tilde{u}_{k} \frac{t^{k}}{k !}-\sum_{k=0}^{n} \tilde{u}_{k, h} \frac{t^{k}}{k !}\right\|_{B_{h}}=\left\|\sum_{k=0}^{n}\left(\tilde{u}_{k}-\tilde{u}_{k, h}\right) \frac{t^{k}}{k !}\right\|_{B_{h}} \leq \sum_{k=0}^{n}\left\|\tilde{u}_{k}-\tilde{u}_{k, h}\right\|_{B_{h}} \frac{T^{k}}{k !} .
$$

Since $\tilde{u}_{k}(x)=(-1)^{k} c^{k} \varphi^{(k)}$ and $\tilde{u}_{k, h}(x)=(-1)^{k} c^{k} Z^{k} \varphi_{h} l(x)$, using lemma 4.1. and 4.2. we obtain the estimation of the approximation error on the some particular iteration step:

$$
\begin{aligned}
& \left\|\tilde{u}_{k}-\tilde{u}_{k, h}\right\|_{B_{h}} \leq|c|^{k}\left\|\varphi^{(k)}-Z^{k} \varphi_{h}\right\|_{B_{h}} \leq|c|^{k} \sqrt{\frac{1}{n+1} \sum_{j=0}^{n}\left[\varphi^{(k)}\left(x_{j}\right)-\varphi_{I}^{(k)}\left(x_{j}\right)\right]^{2}} \leq \\
& \leq|c|^{k} \sqrt{\frac{n+1}{n+1}\left\|\varphi^{(k)}-\varphi_{I}^{(k)}\right\|_{\infty}^{2}} \leq|c|^{k}\left\|\varphi^{(k)}-\varphi_{I}^{(k)}\right\|_{\infty} \leq \frac{|c|^{k}(\operatorname{diam} \Omega)^{n+1-k}}{(n+1-k) !}\left\|\varphi^{(n+1)}\right\|_{\infty} .
\end{aligned}
$$

In addition, we denote $M=\max \{|c| T,(\operatorname{diam} \Omega)\}$ and recalling the binomial property $\sum_{k=0}^{n} \frac{1}{(n-k) ! k !}=\frac{2^{n+1}}{(n+1) !}$ we simplify the estimation of $\left\|u_{n}-u_{h}\right\|_{B_{h}}$ :

$$
\begin{gathered}
\left\|u_{n}-u_{h}\right\|_{B_{h}} \leq \sum_{k=0}^{n}\left\|\tilde{u}_{k}-\tilde{u}_{k, h}\right\|_{B_{h}} \frac{T^{k}}{k !} \leq \sum_{k=0}^{n}\left(\frac{|c|^{k}(\operatorname{diam} \Omega)^{n+1-k}}{(n+1-k) !}\left\|\varphi^{(n+1)}\right\|_{\infty} \frac{T^{k}}{k !}\right)= \\
=\left\|\varphi^{(n+1)}\right\|_{\infty} \sum_{k=0}^{n}\left(\frac{|c|^{k}(\operatorname{diam} \Omega)^{n+1-k}}{(n+1-k) !} \frac{T^{k}}{k !}\right) \leq\left\|\varphi^{(n+1)}\right\|_{\infty} \sum_{k=0}^{n}\left(\frac{M^{n+1}}{(n+1-k) ! k !}\right) \leq
\end{gathered}
$$




$$
\leq M^{n+1}\left\|\varphi^{(n+1)}\right\|_{\infty} \sum_{k=0}^{n}\left(\frac{1}{(n-k) ! k !}\right) \leq\left\|\varphi^{(n+1)}\right\|_{\infty} \frac{(2 M)^{n+1}}{(n+1) !} .
$$

As a conclusion of the above findings we can verify that $\lim _{n \rightarrow \infty}\left\|u_{n}-u_{h}\right\|_{B_{h}}=0$. In fact:

$$
\lim _{n \rightarrow \infty}\left\|u_{n}-u_{h}\right\|_{B_{h}} \leq \lim _{n \rightarrow \infty}\left(\left\|\varphi^{(n+1)}\right\|_{\infty} \frac{M^{n+1} 2^{n+1}}{(n+1) !}\right) \leq\left\|\varphi^{(n+1)}\right\|_{\infty} \lim _{n \rightarrow \infty} \frac{(2 M)^{n+1}}{(n+1) !}=0 .
$$

Finally we have the estimation (4.2), which implies the convergence of the proposed in (4.1) numerical scheme, namely $\lim _{n \rightarrow \infty}\left\|u-u_{h}\right\|_{B_{h}}=0$, since

$$
\lim _{n \rightarrow \infty}\left\|u-u_{h}\right\|_{B_{h}} \leq\left(\lim _{n \rightarrow \infty}\left\|u-u_{n}\right\|_{B_{h}}+\lim _{n \rightarrow \infty}\left\|u_{n}-u_{h}\right\|_{B_{h}}\right)=0 \text {. }
$$

\section{NUMERICAL EXAMPLE}

Let us proceed to the analysis of numerical results. For that purpose, we consider a model problem with the advection equation [21]

$$
\left\{\begin{array}{l}
\text { find function } u=u(x, t) \text { such, that: } \\
\frac{\partial u}{\partial t}+\frac{\partial u}{\partial x}=0, \forall(x, t) \in Q_{T}, \\
\left.u\right|_{t=0}=\sin x,
\end{array}\right.
$$

having the exact solution $u(x, t)=\sin (x-t)$.

The norm of the error of approximating the exact solution $u-u_{h}=u(x, t)-u_{h}(x, t)$ in space $L^{2}\left(Q_{T}\right)$ is calculated by the formula

$$
\left\|u-u_{h}\right\|_{L^{2}\left(Q_{T}\right)}^{2}=\iint_{Q_{T}}\left(u-u_{h}\right)^{2} d x d t,
$$

in the space $L^{\infty}\left(Q_{T, h}\right)$ is calculated at the discretization nodes

$$
\left\|u-u_{h}\right\|_{L^{\infty}\left(Q_{T, h}\right)}=\sup _{(x, t) \in Q_{T, h}}\left|u(x, t)-u_{h}(x, t)\right|,
$$

and the norm in the Sobolev space $W^{1,2}\left(Q_{T}\right)$ [5] is calculated according to

$$
\left\|u-u_{h}\right\|_{W^{1,2}\left(Q_{T}\right)}^{2}=\iint_{Q_{T}}\left[\left(u-u_{h}\right)^{2}+\left(\frac{\partial u}{\partial x}-\frac{\partial u_{h}}{\partial x}\right)^{2}+\left(\frac{\partial u}{\partial t}-\frac{\partial u_{h}}{\partial t}\right)^{2}\right] d x d t .
$$

The exact solution is known for the problem (5.1), thus we use the following rule for evaluating the rate of convergence: $p_{h}=\log _{2}\left(\frac{\left\|u-u_{h}\right\|}{\left\|u-u_{h / 2}\right\|}\right)$. If we get value $\left\|u-u_{h}\right\|=0$ and $\left\|u-u_{h / 2}\right\|=0$, thus the value $0 / 0$ is shown as $\mathrm{NaN}$ (not a number).

The model problem is investigated by means Lax-Wendroff scheme of finite differences method (FDM), method of Lie-algebraic discrete approximations (MLADA), generalized method of Lie-algebraic discrete approximations (GMLADA) and Direct method of Lie-algebraic discrete approximations (DMLADA). The solution of Cauchy problem with the system of differential equations was performed using Mathematica. 
Let us denote $\Delta x=1 /\left(n_{x}-1\right)$ - the step of discretization by space variable, $\Delta t=1 /\left(n_{t}-1\right)-$ the step of discretization by time variable. If discretization steps by both variables are equal then we use $h=\Delta x=\Delta t$ for FDM and GMLADA. Nevertheless $h$ denotes the step of discretization by space variable for MLADA, because time step is chosen automatically while solving the Cauchy problem with the system of differential equation by means of Wolfram Mathematica software.

Table 5.1

Error estimations in $L^{2}\left(Q_{T}\right)$ space

\begin{tabular}{|c|c|c|c|c|}
\hline Step $h$ & FDM & MLADA & GMLADA & DMLADA \\
\hline$h=1 / 2$ & 0.0152981 & 0.0849962 & 0.0396427 & 0.00505709 \\
\hline$h=1 / 4$ & 0.00408866 & 0.00623154 & 0.00053962 & 0.000384316 \\
\hline$h=1 / 8$ & 0.00103819 & $5.7579 \cdot 10^{-6}$ & $2.87577 \cdot 10^{-7}$ & $2.87141 \cdot 10^{-7}$ \\
\hline$h=1 / 16$ & 0.00026054 & $2.16961 \cdot 10^{-5}$ & $2.38063 \cdot 10^{-15}$ & $2.37838 \cdot 10^{-15}$ \\
\hline$h=1 / 32$ & 0.00006510 & - & $3.34574 \cdot 10^{-17}$ & $3.15082 \cdot 10^{-17}$ \\
\hline
\end{tabular}

Table 5.2

Error estimations in $L^{\infty}\left(Q_{T, h}\right)$ space

\begin{tabular}{|c|c|c|c|c|}
\hline Step $h$ & FDM & MLADA & GMLADA & DMLADA \\
\hline$h=1 / 2$ & 0 & 0.46952 & 0.0660836 & 0.0302731 \\
\hline$h=1 / 4$ & 0 & 0.0514178 & 0.0037222 & 0.0034583 \\
\hline$h=1 / 8$ & 0 & $7.90058 \cdot 10^{-5}$ & $4.24574 \cdot 10^{-6}$ & $4.24392 \cdot 10^{-6}$ \\
\hline$h=1 / 16$ & 0 & $4.70088 \cdot 10^{-4}$ & $6.19514 \cdot 10^{-14}$ & $6.19514 \cdot 10^{-14}$ \\
\hline$h=1 / 32$ & 0 & - & $7.07336 \cdot 10^{-34}$ & $7.07335 \cdot 10^{-34}$ \\
\hline
\end{tabular}

Table 5.3

Error estimations in $W^{1,2}\left(Q_{T}\right)$ space

\begin{tabular}{|c|c|c|c|c|}
\hline Step $h$ & FDM & MLADA & GMLADA & DMLADA \\
\hline$h=1 / 2$ & 0.0815902 & 0.383927 & 0.0903126 & 0.026232 \\
\hline$h=1 / 4$ & 0.0394812 & 0.0390588 & 0.0027526 & 0.00263218 \\
\hline$h=1 / 8$ & 0.0195588 & 0.0000578184 & $3.1048 \cdot 10^{-6}$ & $3.1048 \cdot 10^{-6}$ \\
\hline$h=1 / 16$ & 0.00975607 & 0.000338286 & $4.45453 \cdot 10^{-14}$ & $4.45398 \cdot 10^{-14}$ \\
\hline$h=1 / 32$ & 0.00487437 & - & $7.13162 \cdot 10^{-17}$ & $7.76035 \cdot 10^{-17}$ \\
\hline
\end{tabular}


Rates of convergence in $L^{2}\left(Q_{T}\right)$ space

\begin{tabular}{|c|c|c|c|c|}
\hline Step $h$ & FDM & MLADA & GMLADA & DMLADA \\
\hline$h=1 / 2$ & 1.90365 & 3.76974 & 6.19897 & 3.71794 \\
\hline$h=1 / 4$ & 1.97756 & 10.0798 & 10.8738 & 10.3863 \\
\hline$h=1 / 8$ & 1.99448 & -1.91382 & 26.848 & 26.8472 \\
\hline$h=1 / 16$ & 2.00057 & - & 6.15287 & 6.23811 \\
\hline
\end{tabular}

Table 5.5

Rates of convergence in $L^{\infty}\left(Q_{T}\right)$ space

\begin{tabular}{|c|c|c|c|c|}
\hline Step $h$ & FDM & MLADA & GMLADA & DMLADA \\
\hline$h=1 / 2$ & NaN & 3.19085 & 4.15005 & 3.129868 \\
\hline$h=1 / 4$ & $\mathrm{NaN}$ & 9.34609 & 9.77594 & 9.670485 \\
\hline$h=1 / 8$ & $\mathrm{NaN}$ & -2.5729 & 26.0303 & 26.02968 \\
\hline$h=1 / 16$ & $\mathrm{NaN}$ & - & 66.2473 & 66.2473 \\
\hline
\end{tabular}

Table 5.6

Rates of convergence in $W^{1,2}\left(Q_{T}\right)$ space

\begin{tabular}{|c|c|c|c|c|}
\hline Step $h$ & FDM & MLADA & GMLADA & DMLADA \\
\hline$h=1 / 2$ & 1.04723 & 3.29711 & 5.03606 & 3.31699 \\
\hline$h=1 / 4$ & 1.01335 & 9.3999 & 9.79208 & 9.72754 \\
\hline$h=1 / 8$ & 1.00344 & -2.54864 & 26.0547 & 26.0548 \\
\hline$h=1 / 16$ & 1.00108 & - & 9.28683 & 9.16476 \\
\hline
\end{tabular}

From the above tables we can see that proposed numerical method has the same accuracy as Generalized method of Lie-algebraic discrete approximations and even better accuracy for the small count of discretization nodes.

Table 5.7

Count of arithmetic operations for $n_{x}=n_{t}=3$

\begin{tabular}{|c|c|c|}
\hline Step $h=1 / 2$ & GMLADA & DMLADA \\
\hline Error in $L^{2}\left(Q_{T}\right)$ space & 0.0396427 & 0.00505709 \\
\hline Additions, subtractions & 1770 & 159 \\
\hline Multiplications & 1843 & 159 \\
\hline Divisions & 83 & 31 \\
\hline
\end{tabular}

Let us proceed to the main benefit of the proposed numerical scheme, namely the significant reduce of the arithmetic operations count. We compare both methods for solving the problem (5.1), namely the generalized method of Lie-algebraic discrete approximations 
and the direct method of Lie-algebraic discrete approximations for the fixed count of discretization nodes at each of tables.

Table 5.8

Count of operations for $n_{x}=n_{t}=5$

\begin{tabular}{|c|c|c|}
\hline Step $h=1 / 4$ & GMLADA & DMLADA \\
\hline Error in $L^{2}\left(Q_{T}\right)$ space & 0.00053962 & 0.000384316 \\
\hline Additions, subtractions & 170588 & 1151 \\
\hline Multiplications & 171251 & 1115 \\
\hline Divisions & 627 & 131 \\
\hline
\end{tabular}

Table 5.9

Count of operations for $n_{x}=n_{t}=9$

\begin{tabular}{|c|c|c|}
\hline Step $h=1 / 8$ & GMLADA & DMLADA \\
\hline Error in $L^{2}\left(Q_{T}\right)$ space & $2.87577 \cdot 10^{-7}$ & $2.87141 \cdot 10^{-7}$ \\
\hline Additions, subtractions & 27278784 & 12439 \\
\hline Multiplications & 27288163 & 11979 \\
\hline Divisions & 6563 & 739 \\
\hline
\end{tabular}

Table 5.10

Count of operations for $n_{x}=n_{t}=17$

\begin{tabular}{|l|l|l|}
\hline \multicolumn{1}{|c|}{ Step $h=1 / 16$} & \multicolumn{1}{c|}{ GMLADA } & \multicolumn{1}{c|}{ DMLADA } \\
\hline Error in $L^{2}\left(Q_{T}\right)$ space & $2.38063 \cdot 10^{-15}$ & $2.37838 \cdot 10^{-15}$ \\
\hline Additions, subtractions & 1199234704 & 162241 \\
\hline Multiplications & 1199374531 & 158219 \\
\hline Divisions & 83523 & 4931 \\
\hline
\end{tabular}

As it can be seen from the above tables the main benefit of using the proposed numerical scheme is reduced count of arithmetic operations maintaining the same computational properties as a generalized method of Lie-algebraic discrete approximations.

\section{CONCLUSIONS}

Direct method of Lie-algebraic discrete approximations is the combination of classical Method of Lie-algebraic discrete approximation, namely for discretization with respect to space variables and analytical tools for solving Cauchy problem. The key property of such a combination is that method approximates the solution instead of the differential operator; this method brings us significantly closer to the solution of a problem. Such approach allows obtain numerical result with the same high precision and with significantly less computational costs in compare to the generalized method of Lie-algebraic discrete approximations. 
Arkadii Kindybaliuk, M. Prytula

We have presented the application of the direct method of Lie-algebraic discrete approximations for solving the Cauchy problem for advection equation in this paper.

There were compared different numerical schemes (finite difference method, classical method of Lie-algebraic discrete approximations, generalized method of Liealgebraic discrete approximations and direct method of Lie-algebraic discrete approximations) for solving the Cauchy problem for advection equation.

\section{REFERENCES}

1. Бігун О. Метод Лі-алгебричних апроксимацій у теорії динамічних систем / О. Бігун, М. Притула // Математичний вісник НТШ. - Т. 1. - 2004. - С. 24-31.

2. Кіндибалюк А.A. Модифікований метод Лі-алгебричних апроксимацій для еліптичних рівнянь 3 неоднорідними крайовими умовами / А.А. Кіндибалюк, М.М. Притула // Вісн. Львів. ун-ту. Серія прикл. математика та інформатика. 2013. - Вип. 19. - С. 56-67.

3. Кіндибалюк А.А. Застосування узагальненого методу Лі-алгебричних дискретних апроксимацій до розв'язування задачі Коші для двовимірного рівняння адвекції / А.А. Кіндибалюк // Вісн. Львів. ун-ту. Серія механіко-математична. - 2014. Вип. 79. - С. 48-68.

4. Кіндибалюк A.A. Застосування узагальненого методу Лі-алгебраїчних дискретних апроксимацій до розв'язування задачі Коші для рівняння теплопровідності / А.А. Кіндибалюк // Математичні Студії. - 2014. - Т. 42, № 2. - С. 181-194.

5. Люстерник Л.А. Элементы функционального анализа / Л.А. Люстерник, В.И. Соболев. - Москва: Наука, 1965. - 519 с.

6. Люстик М. Функціонально-операторний аналіз проблеми збіжності для методу дискретних апроксимацій Ф. Калоджеро в банахових просторах / М. Люстик, А. Прикарпатський, М. Притула, М. Вовк // Математичний вісник НТШ. - Т. 9. 2012. - C. 168-179.

7. Митропольский А. Алгебраическая схема дискретных аппроксимаций линейных и нелинейных динамических систем математической физики / А. Митропольский, А.К. Прикарпатский, В. Гр. Самойленко // Укр. мат. журн. - 1988. - Т. 40. C. 453-458.

8. Рихтмайер P. Разностные методы решения краевых задач / Р. Рихтмайер, К. Моротон. - Москва: Мир, 1972. - 418 с.

9. Самойленко В.Гр. Алгебраическая схема дискретных аппроксимаций динамических систем математической физики и оценки её точности / В.Гр. Самойленко // Асимптотические методы в задачах мат. физики. - Киев: Инт математики АН УССР. - 1988. - С. 144-151.

10. Тихонов А.Н. Уравнения математической физики: Учеб. пособие для вузов / А.Н. Тихонов, А.А. Самарский. - Москва: Наука, 1977. - 735 с.

11. Bihun O.H. Approximation properties of the Lie-algebraic scheme /O.H. Bihun // Matematychni Studii. - 2003. - Vol. 20, № 1. - P. 85-91.

12. Bihun O.H. Modification of the Lie-algebraic scheme and approximation error estimations / O.H. Bihun // Matematychni Studii. - 2003. - Vol. 20, № 2. - P. 179-184.

13. Bihun O.H. Numerical tests and theoretical estimations for a Lie-algebraic scheme of discrete approximations / O.H. Bihun, M.S. Lustyk // Visnyk of the Lviv University. Series Applied Mathematics and Computer Science. - 2003. - Vol. 6. - P. 3-10. 
14. Bihun $O$. The rank of projection-algebraic representations of some differential operators / O. Bihun, M. Prytula // Matematychni Studii. - 2011. - Vol. 35, Is 1. - P. 9-21.

15. Calogero $F$. Interpolation, differentiation and solution of eigen value problems in more than one dimension / F. Calogero // Lett. Nuovo Cimento. - 1983. -Vol. 38, № 13. P. 453-459.

16. Calogero $F$. Numerical tests of a novel technique to compute the eigen values of differential operators /F. Calogero, E. Franko // Il Nuovo Cins. -1985. - Vol. 89, № 2. - P. 161208.

17. Casas $F$. Solution of linear partial differential equations by Lie-algebraic method / F. Casas // J. of Comp. and Appl. Math. - 1996. - Vol. 76. - P. 159-170.

18. Döö Kristofer Numerical Methods in Meteorology and Oceanography / Kristofer Döös. - Department of Meteorology, Stockholm University, available at http://doos.misu.su.se/pap/compnum.pdf

19. Kalna Eugenia Atmospheric Modelling, Data Assimilation and Predictability / Eugenia Kalnay. - Cambridge University Press, 2003. - 341 p.

20. Kindybaliuk Arkadii Generalized method of Lie-algebraic discrete approximations for solving Cauchy problems with evolution equation / Arkadii Kindybaliuk // Journal of Applied Mathematics and Computational Mechanics. - 2014. - Vol. 12, № 2. - P. 5162.

21. Kindybaliuk Arkadii Application of the generalized method of Lie-algebraic discrete approximations to the solution of the Cauchy problem with the advection equation / Arkadii Kindybaliuk, M. Prytula // Journal of Mathematical Sciences. - 2015. Vol. 204, Is. 3. - P. 280-297.

22. Kindybaliuk Adriana Backward heat equation solution via Lie-algebraic discrete approximations / Adriana Kindybaliuk, Arkadii Kindybaliuk, M. Prytula // Visnyk of the Lviv University. Series Applied Mathematics and Computer Science.- 2017.Vol. 25. - P. 68-81.

23. Prykarpatsky A.K. The Lie-algebraic discrete approximations in computing analysis / A.K. Prykarpatsky, M.M. Prytula, O.O. Yerchenko // Volyn Mathematical Bulletin. 1996. - Vol. 3. - P. 113-116.

24. Wolf $F$. Lie-algebraic solutions of linear Foker-Plank equations / F. Wolf // J. Math. Phys. -1988. - Vol. 29. - P. 305-307.

Стаття: надійила до редколегї 27.05.2018

доопрачьовано 20.06.2018

прийнята до друку 27.06.2018

\section{ПРЯМИЙ МЕТОД ЛІ-АЛГЕБРИЧНИХ ДИСКРЕТНИХ АПРОКСИМАЦІЙ ДЛЯ РОЗ'ЯЗУВАННЯ РІВНЯННЯ АДВЕКЦІї}

\section{Аркадій Кіндибалюк ${ }^{1}$ М. Притула ${ }^{2}$}

13Shape, Польова 21, Київ, 03056, e-mail: kindybaluk.arkadii@outlook.com,

${ }^{2}$ Львівський наиіональний університет імені Івана Франка,

вул. Університетська, 1, Львів, 79000, е-mail: mykola.prytula@gmail.com

Запропоновано й обгрунтовано прямий метод Лі-алгебричних дискретних апроксимацій для чисельного розв'язування задачі Коші для рівняння адвекції, яке задане у замкнутій області $\Omega:=(a, b) \subset R$ з часовою межею $T<+\infty$ 


$$
\begin{cases}\text { знайти функиію } & u=u(x, t) \text { таку, що } \\ u_{t}+c u_{x}=0, & (x, t) \in \Omega_{T}:=\Omega \times(0, T], \\ \left.u\right|_{t=0}=\varphi(x), & \varphi \in W^{\infty, \infty}((-|c| T,|c| T) \cup \bar{\Omega}),\end{cases}
$$

де стала $c \in R$ - швидкість адвекції; $\varphi=\varphi(x)$ - початкова умова.

Ідея прямого методу Лі-алгебричних дискретних апроксимацій полягає у тому, що 3 використанням аналітичних підходів, зокрема методу малого параметра, побудовано наближений аналітичний розв'язок задачі у вигляді степеневого ряду за часовою змінною

$$
u_{n}(x, t)=\sum_{k=0}^{n} \tilde{u}_{k} \frac{t^{k}}{k !}=\varphi(x)-c \varphi^{\prime}(x) t+c^{2} \varphi^{\prime \prime}(x) \frac{t^{2}}{2 !}-c^{3} \varphi^{\prime \prime \prime}(x) \frac{t^{3}}{3 !}+\ldots+(-1)^{n} c^{n} \varphi^{(n)}(x) \frac{t^{n}}{n !} \text {. }
$$

Після цього побудовано його дискретний відповідник з використанням квазізображень елементів алгебри Лі $G=\{1, x, \partial / \partial x\}$

$$
u_{n, h}(t)=\sum_{k=0}^{n} \tilde{u}_{k, h} \frac{t^{k}}{k !}=\varphi_{h}-c Z \varphi_{h} t+c^{2}(Z)^{2} \varphi_{h} \frac{t^{2}}{2 !}-c^{3}(Z)^{3} \varphi_{h} \frac{t^{3}}{3 !}+\ldots+(-1)^{n} c^{n}(Z)^{n} \varphi_{h} \frac{t^{n}}{n !},
$$

де матриця $Z$ апроксимує диференціальний оператор $d / d x$.

Доведено, що обчислювальна схема збіжна, а норма похибки характеризується оцінкою

$$
\left\|u-u_{h}\right\|_{B_{h}} \leq \frac{|c|^{n+1} T^{n+1}+(2 \max \{|c| T,(\operatorname{diam} \Omega)\})^{n+1}}{(n+1) !}\left\|\varphi^{(n+1)}\right\|_{\infty} .
$$

Обчислювальні експерименти засвідчили, що при однакових показниках точності та збіжності, характерних для узагальненого методу Лі-алгебричних дискретних апроксимацій вдалося суттєво зменшити кількість арифметичних операцій з використанням пропонованого нами підходу.

Ключові слова: прямий метод Лі-алгебричних дискретних апроксимацій, рівняння адвекції, скінченновимірне квазізображення, поліном Лагранжа, метод малого параметра, факторіальна збіжність. 